\title{
esboços
}

histórias em contextos globais

\section{CENSURA E PROPAGANDA NO CINEMA COLONIAL DO ESTADO NOVO PORTUGUÊS: UMA ENTREVISTA COM MARIA DO CARMO PIÇARRA}

Censorship and propaganda in colonial cinema during the Portuguese Estado Novo: an interview with Maria do Carmo Piçarra

\section{ENTREVISTADA}

Maria do Carmo Piçarra

Universidade Autónoma de Lisboa

carmoramos@gmail.com

(D) https://orcid.org/0000-0002-7875-9629

\section{ENTREVISTADOR}

Luiz Felipe Florentino Universidade Federal de Santa Catarina

I.f.florentino@outlook.com (D) https://orcid.org/0000-0001-6213-8628

PALAVRAS-CHAVE: Cinema. Colonialismo. Estado Novo.

KEYWORDS: Cinema. Colonialism. Estado Novo. 
$\mathbf{A}$ professora historiadora Maria do Carmo Piçarra é licenciada, mestre e doutora em Ciências da Comunicação pela Faculdade de Ciências Sociais e Humanas da Universidade Nova de Lisboa. Atualmente encontra-se vinculada ao Centro de Estudos de Comunicação e Sociedade da Universidade do Minho. Possui larga experiência na área de história do cinena, abordando, sobretudo, propaganda e censura no Estado Novo português, tendo sido contemplada com bolsas de pesquisa da Fundação Calouste Gulbenkian, da Fundação para a Ciência e a Tecnologia de Portugal e da Fundação Oriente. É autora de uma série de artigos e dos livros Azuis ultramarinos: propaganda colonial e censura no cinema do Estado Novo (Edições 70, 2015), Salazar vai ao cinema II: a política do espírito no Jornal Português (DrellaDesign, 2011) e Salazar vai ao cinema: o Jornal Português de actualidades filmadas (Minerva Coimbra, 2006). Piçarra teve a gentileza de conceder, por e-mail, a entrevista abaixo no primeiro semestre de 2018.

\section{Professora, primeiramente a senhora poderia nos falar sobre sua trajetória acadêmica e profissional? Gostaríamos que nos falasse sobre os caminhos já percorridos e os que ainda pretende percorrer.}

O meu percurso profissional iniciou-se, cedo, como jornalista. Ainda durante os estudos universitários comecei a escrever sobre questões sociais, num jornal local, de pequena escala. Posteriormente, especializei-me na crítica cinematográfica, num dos semanários de referência em Portugal e em revistas de cinema (fui crítica da primeira edição portuguesa da Première desde o início até à extinção, ou seja, entre 1996 e 2006). Durante o percurso jornalístico sempre me perturbou o imediatismo, a falta de reflexão. Por isso, logo no início da minha carreira de jornalista concorri, com sucesso, a uma bolsa do Serviço de Belas Artes da Fundação Calouste Gulbenkian, para estudar algo que cruzava cinema e jornalismo: a primeira série de atualidades cinematográficas de propaganda do Estado Novo português, Jornal Português, que existiu entre 1938 e 1951, e que era mostrada nos cinemas antes da projeção dos longas-metragens de ficção fazendo a propaganda dos acontecimentos que a ditadura portuguesa queria promover. O estudo acabou por servir de base à minha tese de mestrado numa época em que continuava a ser jornalista e não pensava em seguir uma carreira acadêmica.

O meu percurso acadêmico é muito recente. Iniciou-se em 2008, de algum modo, já após a edição, em livro (o primeiro), da minha tese de mestrado, com o título Salazar vai ao cinema: o Jornal Português de actualidades filmadas (2006). Foi motivado por dois fatores: a transformação profunda do jornalismo e do mercado editorial; e um trabalho desenvolvido entre 2006 e 2008 num bairro de barracas (uma favela) com crianças e jovens de origem guineense e cabo-verdiana em que tomei contato com denúncias (e práticas) de racismo na escola, sobretudo. No âmbito desse trabalho voltei à pesquisa. Durante um ano, um dia por semana, ia ver filmes de atualidades de propaganda no Arquivo Nacional de Imagens em Movimento (ANIM), procurando analisar como é que surgiu uma ideia muito comum em Portugal: a de que não somos um país racista. Essa ideia foi criada pela ditadura portuguesa através do aproveitamento das teorias do sociólogo brasileiro Gilberto Freyre, que cunhou mesmo a designação luso-tropicalismo para designar um suposto "modo português de estar no mundo". Esse aproveitamento ideológico foi projetado através do cinema. Durante o doutoramento, que iniciei em 2008, com uma bolsa de estudo 
da Fundação Portuguesa para a Ciência e Tecnologia (FCT), estudei então como se processou essa projeção cinematográfica em atualidades filmadas de propaganda sobre o modo como eram filmadas as ex-colônias portuguesas, as pessoas (colonos e colonizados) que nelas viviam, os aspectos culturais e outros, etc. - contrapondo-Ihe três casos de filmes feitos em Angola e Moçambique, quando eram colônias portuguesas, censurados e proibidos durante a ditadura e que não foram reabilitados após o advento da democracia, em 25 de abril de 1974. Esse estudo deu origem à edição de Azuis ultramarinos: propaganda colonial e censura no cinema do Estado Novo (2015). Entretanto, iniciei uma pesquisa comparativa sobre os cinemas coloniais português, francês e inglês e influências destes últimos na produção portuguesa. É o que estou fazendo ainda.

Pelo caminho, coordenei a trilogia Angola: o nascimento de uma nação. Ao contrário do caso do cinema moçambicano, que emergiu após a independência do país, e que está razoavelmente estudado, não havia um estudo desenvolvido para o caso angolano. Havia publicações importantes, do intelectual angolano José Mena Abrantes, que lançaram as bases para um estudo mais alargado, para o qual, eu e o Jorge António, realizador português radicado em Angola, convidamos vários investigadores a contribuir. A iniciativa e toda a produção desta trilogia, que contempla os volumes "O cinema da propaganda", "O cinema da libertação" e "O cinema da independência", foi do Jorge António. Eu, devido aos meus contatos no mundo acadêmico, concentrei-me mais na seleção de autores e coordenação das pesquisas bem como na edição e revisão final de cada capítulo.

Referi antes à pesquisa que estou fazendo. No âmbito da mesma tenho organizado vários ciclos de filmes, debates, conferências e publicações, a mais relevante da qual foi (Re)imagining African Independence: Film, Visual Arts and the Fall of the Portuguese Empire, co-editado com a Teresa Castro pela editora Peter Lang. Importa-me muito partilhar os resultados das pesquisas não só com os meus colegas investigadores, mas também em espaço público. A minha pesquisa é um contributo para uma reavaliação das concepções identitárias que a ditadura portuguesa do Estado Novo promoveu e que ainda hoje marcam o modo como nos concebemos como indivíduos e cidadãos e como acolhemos (ou não) pessoas de outras nacionalidades, raças, religiões, etc. Interessa-me muito criar um sítio em linha onde estes materiais - filmografias, filmes, descritivos respectivos, textos críticos e informativos sobre esta produção, além de ferramentas que promovam a literacia visual - sejam disponibilizados a todos os falantes da língua portuguesa, de modo a que os materiais não estejam tão dispersos, por um lado, em tantos arquivos físicos, e por outro lado, de forma a permitir acesso a quem não possa deslocar-se. Também estou a iniciar uma abordagem mais aprofundada dos filmes feitos no Oriente com influência portuguesa. Não me interessa apenas abordar estes materiais historicamente, mas integrá-los numa linha do tempo que permita perspectivar o que somos hoje, comunidade de língua portuguesa num mundo global, a partir das representações que usam a imagem em movimento, incluindo o cinema, produção audiovisual e as artes visuais no geral.

Quais as principais dificuldades e vantagens para um investigador que utiliza o cinema enquanto fonte, que a senhora poderia destacar? 
As dificuldades são várias. Elenco algumas, sem a preocupação de ser exaustiva. Devido aos custos de restauro e das políticas de conservação, nem sempre é possível ver os filmes em geral, e os coloniais em particular, devido ao mau estado de conservação dos materiais. Quando os recursos são escassos - como é o caso português - privilegia-se o restauro de obras de autor consideradas fundamentais pela historiografia que, nem sempre, tem uma perspectiva crítica ou de conhecimento profundo sobre as coleções. O gênero documental de propaganda ou promoção colonial (seja na vertente turística, econômica, etc.) não é, em geral, uma prioridade. Por outro lado, mesmo filmes de autores de qualidade e importância histórica estão ainda num limbo: eram filmes malditos durante certos períodos históricos e, em períodos subsequentes, a sua recuperação pela história do cinema não é imediata. O trabalho que faço tem também essa dimensão, de revalorização de certas obras esquecidas nos arquivos.

Outra dificuldade tem a ver com a dispersão dos arquivos. Várias instituições diferentes detêm coleções que não estão fisicamente concentradas. Há que ir procurá-las. Por vezes é mesmo preciso descobrir que existem porque não há informação pública sobre a sua existência, não há filmografias, muito menos fichas técnicas e descritivas. Outra dimensão do meu trabalho é criar filmografias, divulgar coleções existentes. Gostaria de coordenar um projeto com investigadores que garantissem a inventariação e criação de descritivos de filmes ou a correção de alguns existentes que estão incompletos ou têm erros. Mesmo no caso da Cinemateca Portuguesa, não existe uma filmografia pública relativa à chamada coleção colonial da instituição. Os investigadores têm de indagar, caso a caso, que títulos existem.

A dispersão não é apenas a dos arquivos fílmicos, mas da documentação relativa à produção dos filmes. Um exemplo: há, na Cinemateca Portuguesa, vários filmes relativos às ex-colônias portuguesas, e em várias línguas, do realizador francês Pascal-Angot. A documentação relativa à produção destes filmes, mantida confidencial pelo Estado Novo, está dispersa em arquivos como a Torre do Tombo e o Arquivo Histórico-Diplomático, pelo menos (é possível que outros arquivos que não consultei tenham mais documentação). Sem estes documentos, a análise de imagem não basta.

Outras dificuldades são o fato de não haver um único modelo de análise de imagem e subsistir um modelo positivista, ainda hoje dominante, que procura garantir que o rigor dependa de uma metodologia mais quantitativa do que qualitativa; além do cinema continuar a ser desconsiderado como fonte histórica e de merecer pouca credibilidade e atenção por alguma parte de academia.

Facilidades? Haver muitos filmes, independentemente da sua qualidade artística, que merecem um olhar, merecem ser descobertos e analisados no sentido de promover um melhor conhecimento, quer da subjetividade humana quer do modo como nos projetamos como comunidades imaginadas, na perspectiva de Benedict Anderson.

O Estado Novo português perdurou por quatro décadas, sendo assim, a forma como este regime político lidou com o cinema, ao longo de todos esses anos, certamente não foi homogênea. Em linhas gerais, que considerações a senhora poderia fazer sobre esta relação estabelecida entre o Estado Novo e o cinema, destacando possíveis continuidades e rupturas?

Não, não foi homogênea. Após a criação do Secretariado da Propaganda Nacional (SPN), tendo como diretor o intelectual António Ferro, houve um esforço no 
sentido de usar o cinema como instrumento de propaganda. Durante esse período era internacionalmente aceita e estimulada essa prática, mesmo em países democráticos. Pela negativa, o Estado Novo português usa a censura para condicionar o que pode ver-se nas salas de cinema. Pela positiva, investe primeiro na produção direta de documentários e atualidades de propaganda além de promover a produção de dois filmes de ficção de propaganda assumida do Estado Novo: A revolução de maio (1938) e Feitiço do império (1940). Toda essa produção é mostrada através de dispositivos do regime destacando-se um dispositivo ambulante de projeção, o Cinema do Povo, que começa a circular pelo país, copiando uma prática alemã, após o início da Guerra Civil em Espanha, em 1936, e visando usar o cinema para combater o comunismo. Os filmes são também mostrados no âmbito da participação portuguesa em grandes exposições internacionais ou outras, organizadas pelo SPN e por Ferro, no âmbito daquilo que ele desenhou e designou como "política do espírito". Entretanto, define-se um padrão de filme nacional enquanto, com muito atraso, já na década de 1940, se cria o Fundo do Cinema Nacional, que distribui alguns apoios à produção cinematográfica portuguesa. A partir de 1951, após o afastamento de Ferro do SPN, entretanto transformado em Secretariado Nacional da Informação (SNI), e com a ausência de uma política cultural que veio substituir a "política do espírito", há uma continuidade quanto a algumas opções propagandistas de uso da cultura. Porém, dado que os sucessores de Ferro não têm a largueza de vistas deste nem a sua grande cultura, sendo, sobretudo funcionários do regime mais do que intelectuais com um conhecimento das práticas culturais em todo o mundo, como foi Ferro, há uma fragilização do investimento no cinema. É, no entanto, muito importante o apoio que alguns artistas e realizadores recebem do SNI e também da Fundação Calouste Gulbenkian, que é privada, para estudarem fora de Portugal. É assim que se formam vários futuros criadores do Cinema Novo português. O Estado Novo, por sua vez, acaba por, confidencialmente, canalizar os apoios ao cinema para uma produção cinematográfica de propaganda garantida por realizadores estrangeiros, sobretudo Jean-Noel Pascal-Angot, Jean Leduc e mesmo Jean Manzon, francês radicado no Brasil. Esta produção confidencial não estava estudada. Desconhecia-se os contornos do seu modo de produção e através da minha pesquisa em arquivos de documentação pública comecei a descobrir os contratos secretos relativos à sua produção. Tratou-se de uma produção para projetar internacionalmente a ideia de que Portugal não tinha colônias - do Minho a Timor tudo era Portugal - e que havia, supostamente, uma maneira portuguesa de estar no mundo. De certo modo, trata-se de projetar cinematograficamente o luso-tropicalismo e o projeto social e econômico em curso nas então colônias portuguesas. Entretanto inicia-se a emissão de programas pela Rádio Televisão de Portugal e o regime passa a instrumentalizar cada vez mais este meio para influenciar internamente a opinião pública, em detrimento do cinema, o que não impede que filmes como Chaimite tenham ampla difusão televisiva.

Simultaneamente, os realizadores portugueses do Novo Cinema mostravam uma realidade urbana, sobretudo, de um país triste, dilacerado pela guerra colonial, fechado sobre si. Esta geração, porém, consegue certa notoriedade internacional quando apresenta os seus filmes nos festivais de cinema internacionais. Quando abordam a Fundação Gulbenkian pedindo-lhe um apoio à produção cinematográfica que o Estado pouco ou nada suporta - mantém-se a ideia de que só os filmes nacionalistas poderão ser apoiados e há casos de censura, como aquela de que foi alvo Catembe (1964), de Manuel Faria de Almeida, o filme que sofreu mais cortes da história do cinema, que ditam que 
esta nova geração não conte com o Fundo do Cinema Nacional - acabam por conseguir apoio para a criação de uma cooperativa de cinema, gerindo eles próprios, entre si, que projetos são filmados em função de um orçamento dispensado pela Fundação. Esta geração acaba por conseguir também a criação de uma Escola de Cinema nacional, passando a assegurar o ensino. Na verdade, quando se dá a Revolução que restaura o regime republicano e a democracia em Portugal, a geração do Cinema Novo já se tinha conseguido impor e mudado o panorama do cinema, embora continuasse a estar limitada pela censura e cerceada em termos de liberdade de expressão havendo vários casos de filmes censurados ou que não estrearam antes do 25 de abril de 1974 devido aos temas abordados por eles, sobretudo.

Através de suas pesquisas, nomeadamente as publicadas em Azuis ultramarinos, podemos observar que a senhora contribuiu para um maior entendimento das relações estabelecidas entre o Estado Novo português e o cinema, no que tange a propaganda colonial. No entanto, a senhora acredita que esta estratégia propagandística, em que o cinema era utilizado como uma espécie de ferramenta política, surtiu efeito? Esta propaganda atingiu com êxito grande parte da população a qual era destinada?

Sem dúvida. Parte significativa do que se considera a identidade portuguesa - ou que os portugueses consideram ser a sua identidade - foi forjada no âmbito de um revisionismo histórico promovido consciente e ativamente pelo Estado Novo, sobretudo durante o período da "política do espírito" de António Ferro. Pensadores como José Gil e Eduardo Lourenço têm escrito sobre isso, e, no caso do primeiro, de um certo "medo de existir", em Portugal que, no entendimento de Gil, decorre da formatação e dos constrangimentos a que estivemos submetidos durante a ditadura. Eu iria mais atrás - a pobreza, o analfabetismo, etc., são anteriores e também explicam muito do que somos ainda hoje - mas concordo com a ideia de que os dispositivos de propaganda e repressão do Estado Novo, de que o cinema fez parte, tiveram um forte impacto. A televisão, quando surgiu, foi outro dispositivo usado nesse sentido. Creio que o uso do cinema e da televisão, articulado com o de outros dispositivos - também, pela negativa, com o da censura - foram determinantes para a concepção de uma certa ideia de Portugal, da portugalidade, que tem ressonâncias ainda hoje numa certa concepção da lusofonia, em que, por via da língua mas também em termos de disseminação do conhecimento e da cultura, é excessiva a centralidade de Portugal, numa comunidade falante da língua portuguesa.

Professora, por mais que Jorge Brum do Canto, o idealizador do filme Chaimite (1953), tenha negado envolvimento político com o Estado Novo, a senhora acredita que esta obra cinematográfica especificamente, tenha sido utilizada pelo governo português para fins propagandísticos? As pressões de potências internacionais, que defendiam o término da dominação colonial pós Segunda Guerra Mundial, podem ter sido decisivas neste contexto?

Jorge Brum do Canto era monárquico e não sendo um homem do regime do Estado Novo era, porém nacionalista, havendo coincidência de certos valores seus com os do regime. Do seu nacionalismo fazia parte uma valorização do colonialismo português que incluiu o elogio de figuras militares que contribuíram para manter o 
domínio colonial português em territórios onde surgiram revoltas, como foi o caso de Moçambique, o que ele trata no seu filme Chaimite. Este filme se beneficiou de apoio do Fundo do Cinema Nacional - integrava-se inteiramente na concepção do filme a apoiar e promover o Estado Novo. Como tal, a sua realização foi supervisionada por Júlio Cayola, figura do regime e antigo Agente Geral das Colónias. Ou seja, além dos consultores militares de que Brum do Canto se socorreu para a reconstituição de certos acontecimentos, também este funcionário do SNI supervisionou a realização do filme, tendo interferido em certas opções de reconstituição, valores promovidos, etc. Brum do Canto queixou-se, em entrevista a Jorge Seabra, de que o filme foi objeto de censura pelo Estado Novo. Eu estudei Feitiço do império, obra de propaganda explícita do Estado Novo e produzida diretamente pelo regime, com realização do cineasta do regime, António Lopes Ribeiro. O guião original do filme também incluía sequências que foram alteradas ou modificadas, de modo a conformar-se com os valores promovidos e pelos quais os censores zelavam à posteriori, mas também à priori. Não é, pois, estranho que, à luz do que era a sua prática, o Estado tenha interferido e condicionado certas opções quanto à realização de Chaimite, uma vez que este contou com apoio financeiro público.

Chaimite foi amplamente exibido pelo Cinema do Povo do Estado Novo e foi também o primeiro filme português mostrado pela televisão em Portugal, após o início das transmissões.

O regime do Estado Novo estava consciente de que a sua manutenção estava diretamente ligada à sobrevivência do colonialismo português. Quando Chaimite fica pronto é, pois, usado para projetar uma imagem da história de Portugal, mas também é um elogio à instituição militar, com a qual Salazar manteve sempre uma relação tensa tendo sempre que negociar benefícios - como a renovação do armamento, durante a Segunda Guerra Mundial - enquanto ia retirando direitos dos militares, nomeadamente quanto à ocupação de certos cargos públicos a que antes tinham acesso por lei. Porém, o discurso de Chaimite, que inclui também o elogio da coragem dos colonos portugueses, nada tem a ver com o luso-tropicalismo que, nessa altura, começa a ser a doutrina do Estado, após o convite, em 1951, pelo Ministro do Ultramar - nessa altura há uma revisão constitucional e o termo colônias é substituído por ultramar, para reforçar a ideia de continuidade entre a metrópole, na Europa, e as "províncias ultramarinas" (como passam a designar-se as então colônias) na África e Ásia -, a Gilberto Freyre para uma viagem, de um ano, pelos territórios portugueses. Esse convite, contextualize-se, surge por causa da questão de Goa. Quando a União Indiana se torna independente, em 1948, reclama que Portugal devolva Goa, Damão e Diu. As questões diplomáticas e escaramuças que tal provoca, face à recusa portuguesa, ditam o convite a Freyre que, em Goa, numa conferência, usa, pela primeira vez, a palavra luso-tropicalismo. Os livros que publica (Aventura e rotina e Um brasileiro em terras de Portugal, sobretudo) na sequência desta viagem, e cuja linguagem foi cuidadosamente revista no sentido de usar a terminologia surgida após a revisão da Constituição portuguesa, revelam um grande enfoque na questão goesa e na proximidade cultural encontrada entre Brasil e a "Índia portuguesa". Em suma, Chaimite é um filme nacionalista, de apoio a instituições que sustentam o regime e que visa também o elogio do colono português em África e por isso é financiado e amplamente projetado pelo regime numa altura de questionamento internacional à posse de colônias. Porém, o seu discurso não é 
ainda luso-tropicalista, e não projeta, de todo, a retórica freyriana simplificada que o Estado Novo passará a projetar via cinema.

Por último gostaríamos de abordar o papel do revisionismo histórico. Anteriormente a senhora destacou que em Portugal há uma ideia amplamente difundida sobre a característica branda e sui generis do colonialismo português. Em sua opinião, ao que se atribui a permanência deste discurso nos dias atuais e em que medida o revisionismo histórico ajuda a combatê-lo?

Esta permanência deve-se à falta de uma análise crítica do colonialismo português durante 30, 40 anos após a Revolução do 25 de abril de 1974. Só recentemente, e em várias áreas do conhecimento, surge um interesse mais generalizado em olhar criticamente, e refletir, sobre o passado colonial recente. Após o regresso da democracia e na sequência de uma longa ditadura, o país enfrentou muitos desafios - políticos, sociais, econômicos, culturais, educativos - que o fez virar para a Europa e voltar um pouco as costas à reavaliação da história recente. Nem mesmo o regresso de cerca de um milhão de "retornados" das colônias, a emigração das ex-colônias para Portugal, motivou uma reavaliação identitária, das memórias, e do passado político. Tal permitiu que a retórica luso-tropical do Estado Novo continuasse tendo eco e escamoteou o debate necessário quando a lusofonia se afirmou como projeto no âmbito de uma comunidade alargada de língua portuguesa. $\mathrm{O}$ facto dos países africanos de língua portuguesa terem vivido guerras no pós-independências facilitou a manutenção dessa retórica. Por outro lado, o passado colonial, no que respeita ao Brasil, porque mais remoto (mas que nem por isso deixa de ser marcante) não tem sido debatido o suficiente.

Creio que as pesquisas atualmente em curso em todos os países de língua portuguesa e que abordam o passado colonial e as suas marcas no discurso identitário começam agora a circular e a permitir uma reavaliação crítica. O uso do cinema como fonte de pesquisa dará certamente um contributo importante para um questionamento necessário.

\section{NOTAS}

Maria do Carmo Piçarra: Doutora. Professora, Universidade Autónoma de Lisboa, Departamento de Ciências da Comunicação, Lisboa, Portugal. Rua de Santa Marta, 47, 1150-140, Lisboa, Portugal.

Luiz Felipe Florentino: Graduando, Universidade Federal de Santa Catarina, Centro de Filosofia e Ciências Humanas, Departamento de História, Florianópolis, SC, Brasil. Campus Universitário Trindade, Laboratório de História Social do Trabalho e da Cultura, Bloco D, Sala 310, 88040-900, Florianópolis, SC, Brasil.

Como citar: PIÇARRA, Maria do Carmo. Censura e propaganda no cinema colonial do Estado Novo português: uma entrevista com Maria do Carmo Piçarra. Esboços, Florianópolis, v. 26, n. 41, p. 214222, jan./abr., 2019. Entrevistador: Luiz Felipe Florentino.

FINANCIAMENTO

Não se aplica. 


\section{CONFLITO DE INTERESSES}

Não se aplica.

\section{AGRADECIMENTOS}

Ao professor Sílvio Marcus de Souza Correa que, por seu intermédio, tornou esta entrevista possível.

\section{LICENÇA DE USO}

Este artigo está licenciado sob a Licença Creative Commons CC-BY Internacional 4.0. Com essa licença você pode compartilhar, adaptar, criar para qualquer fim, desde que atribua a autoria da obra.

\section{PUBLISHER}

Universidade Federal de Santa Catarina. Programa de Pós-graduação em História. Portal de Periódicos UFSC. As ideias expressadas neste artigo são de responsabilidade de seus autores, não representando, necessariamente, a opinião dos editores ou da universidade.

\section{HISTÓRICO}

Recebido em: 29 de julho de 2018

Aprovado em: 15 de agosto de 2018 